\title{
Optimization of Heavy Metals Removal from Aqueous Solution Using Synthesized Chromic Oxide and Chromic Oxide - Lophira Alata Carbonized Sawdust Nanoparticles
}

\author{
James M Okuo $^{1} \quad$ Moses Okponmwense $^{1} \quad$ Bala Anegbe $^{2} \quad$ Ufuoma Ugbune $^{3}$ \\ 1.Environmental Analytical Research Laboratory, Department of Chemistry, University of Benin, Benin City \\ 2.Department of Basic and Industrial Chemistry, Western Delta University, P.M.B. 10, Oghara, Delta State \\ 3.Department of Chemistry, Delta State College of Education, Mosogar, Nigeria
}

\begin{abstract}
This research was designed to ascertain the removal efficiency of $\mathrm{Cd}^{2+}$ and $\mathrm{Pb}^{2+}$ ion in aqueous system with the use of chromic oxide nanoparticle $(\mathrm{CN})$ and chromic oxide-lophiraalata carbonised sawdust nanocomposite (CLN) synthesized by co-precipitation and thermal degradation methods. The physicochemical characterization of the synthesized chromic oxide nanoparticle and chromic oxide-lophiraalata carbonised sawdust nanocomposite (CN and CLN) were evaluated using x-ray diffractograms (XRD), scanning electron microscope (SEM) and Fourier Transform infrared spectrophotometer (FTIR). The obtained CN and CLN were crystalline, amorphous, smooth and spherical in shape with very small particles inapparently soft agglomerates with a size of 7.7 and 12.05 $\mathrm{nm}$ respectively. The amount of $\mathrm{Cd}^{2+}$ and $\mathrm{Pb}^{2+}$ ions before and after treatment of the polluted water was evaluated using atomic absorption spectrometer (AAS). The adsorption property of CN and CLN was studied using isotherm models and Response Surface Methodology (RSM) Analysis. The isotherm models revealed that the adsorption process of $\mathrm{Cd}^{2+}$ and $\mathrm{Pb}^{2+}$ ions onto $\mathrm{CN}$ and $\mathrm{CLN}$ was a physical process (physiosorption), favorable and exothermic. The energy of affinity for $\mathrm{Pb}^{2+}$ ions on both nanoparticles was higher. The response surface methodology analysis for $\mathrm{CN}$ revealed that the cadmium ions were slightly more adsorbed and removed from the heavy metal polluted water compared to lead ions. This observation was in agreement with the $\mathrm{k}_{\mathrm{F}}$ values obtained from Freundlich isotherm in which the $\mathrm{k}_{\mathrm{F}}$ value for cadmium ions (59.52) was higher than that of lead (51.99). However, the response surface methodology analysis for CLN revealed that the $\mathrm{Pb}^{2+}$ ions were more adsorbed compared to $\mathrm{Cd}^{2+}$ ions with optimum adsorption capacities of 191.50 and $66.20 \mathrm{mg} / \mathrm{g}$ respectively. These values also agreed with the $\mathrm{K}_{\mathrm{F}}$ values obtained from Freundlich isotherm. This implies that CLN was more effective in the removal of $\mathrm{Pb}^{2+}$ ions.
\end{abstract}

Keywords: Chromic oxide, Nanoparticle, Optimization, Response Surface Methodology, Isotherm

DOI: $10.7176 /$ JNSR/10-2-06

Publication date: January $31^{\text {st }} 2020$

\section{Introduction}

Water is one of the most important resources for human life, despite its abundance on the earth, majority of the water bodies are polluted (Mohan et al. 2011). Water that is free of pollutant is indispensable to human health (Savage \& Diallo 2005). The parameters of polluted water vary widely and depend upon the source from which it is generated. Commonly they are pathogenic and non-pathogenic microorganisms, organic or inorganic. If polluted water is disposed untreated its constituents create a great threat to living beings and the environment (Sushma \& Richa 2015). Water pollution research and development of remedial techniques has become a necessity to bring about an improvement in the quality of water for human existence and longevity. Different methods adopted for heavy metals removal from aqueous medium include membrane separation, coagulation, flocculation, chemical treatment, filtration and adsorption (Sadegh et al.2014). Adsorption has advantage over the other methods because of simple design, low cost and no sludge formation. Different natural and synthetic materials have been used to remove heavy metals these include clay, seaweed, biomass, activated carbon, resin and mesoporous silica. However information about using nanomaterials for adsorption of heavy metals in aqueous system in developing country is still at the preliminary stage. Thus there is need for the development of affordable nanomaterials with increased affinity, capacity and selectivity for heavy metals and other contaminants. Nanotechnology has the potential to revolutionize the remediation of polluted or contaminated water, agriculture and food industry (Wani $\&$ Shah, 2012). The applications of nanoparticles in solving environmental problem is still a new area, it is growing rapidly and the potential of nanoparticles to react with pollutants in the air, soil, and water with the aim of transforming them into harmless compounds is currently being researched. Nanotechnology could be applied at both ends of the environmental spectrum, to clean up existing pollution and to decrease or prevent its generation. Matters at nano-scale possesses exceptional properties such as small size effect, large surface effect and quantum tunnel effect and provide a variety of surprising and interesting uses (Sovan et al. 2011; Salata 2004; Rathore et al. 2012). Nanoparticles tend to aggregate and interact with environmental media because of their charged surface and surface potential (Cornell \& Schwertmann, 2003). Nanoparticles characteristically have very high surface area 
to volume ratios, which when compared to their bulk counterparts and their properties can vary dramatically under different electrical, photological, and thermodynamic conditions (Rathore et al. 2012; Mahdi et al. 2012). Several synthetic methods have been developed for generation of nanoparticles, such as chemical, photochemical, electrochemical, radiolytic, co-precipitation, sol gel, mechanochemical reaction and sonochemical methods etc. (Ramesh et al. 2012; Rakesh \& Netkal 2013). The objective of this study was to synthesize, characterize CN and CLN and evaluate the efficiency of $\mathrm{CN}$ and $\mathrm{CLN}$ in removing $\mathrm{Cd}^{2+}$ and $\mathrm{Pb}^{2+}$ ions from polluted system using isotherm models and response surface methodology.

\section{Materials and Methods}

\subsection{Adsorbates Preparation and Characterization}

All reagents were of analytical grade and obtained from BDH and used without further purification.

\subsection{Chromic Oxide Nanoparticle (CN) and Chromic Oxide-lophira alata Carbonized Sawdust Nanocomposite (CLN) Synthesis}

Chromium (III) oxide nanoparticle (CN) was synthesized using the thermal degradation method adapted from Tavares et al. (2014) and Sadjadi \& Khalilzadegan (2015), with slight modifications. A solution of 5.0 mmole of $\mathrm{Cr}\left(\mathrm{NO}_{3}\right)_{3} .9 \mathrm{H}_{2} \mathrm{O}$ was dissolved in $40 \mathrm{ml}$ of distilled water to obtain chromic $\left(\mathrm{Cr}^{3+}\right)$ ions solution A. Solution B was made by dissolving 20.0 mmole of $\mathrm{NaOH}$ in $50 \mathrm{ml}$ of distilled water. Solution B was added drop wise into a 200 $\mathrm{ml}$ reaction vessel containing solution $\mathrm{A}$ at a rate of one drop per second under vigorous stirring (using Stuart SD162 heat-stir) at 1300rpm. The reacting system was further stirred at $90{ }^{\circ} \mathrm{C}$ for $2 \mathrm{hr}$. $\mathrm{The} \mathrm{Cr}(\mathrm{OH})_{3}$ nanoparticle formed was allowed to cool for at least $6 \mathrm{hr}$ after which the product was separated by centrifugation at 5,800 rpm for 15 min (using MPW-53) and washed three times with distilled water. The synthesized $\mathrm{Cr}(\mathrm{OH})_{3}$ nanoparticle was dried in an oven at $105^{\circ} \mathrm{C}$ for $6 \mathrm{hr}$ to avoid the oxidation of $\mathrm{Cr}^{3+}$ to $\mathrm{Cr}^{6+}$. Finally the $\mathrm{Cr}(\mathrm{OH})_{3}$ nanoparticle was calcined at $400^{\circ} \mathrm{C}$ for $5 \mathrm{hr}$ to obtain $\mathrm{CN}$ which was allowed to cool in a desiccators for $24 \mathrm{hr}$.

In order to modify the surface of chromic oxide nanoparticle, so as to reduce or eliminate aggregation/agglomeration as well as water uptake, the post-precipitation addition method of capping metal oxide nanoparticle adapted from Li et al. (2013), with slight modifications was used in modifying the surface of the synthesized chromic oxide nanoparticle. Polyvinyl alcohol (PVA) was used as its capping agent. $1.5 \%$ solution of polyvinyl alcohol (PVA) was added to the chromic oxide nanoparticle until slurry or paste was formed. The slurry was oven dried at $105^{\circ} \mathrm{C}$ for $12 \mathrm{hr}$ and allowed to cool in a desiccator for $24 \mathrm{hr}$. The dried polyvinyl alcohol (PVA) capped chromic oxide nanoparticle was ground and sieved through 400 mesh size sieve.

Chromic oxide-lophira alata carbonized sawdust nanocomposite (CLN) was prepared by the co-precipitation method adapted from Moafi et al. (2016) and Hasanzadeh et al. (2016), with slight modifications. About 20 mmole of sodium hydroxide $(\mathrm{NaOH})$ in $50 \mathrm{ml}$ distilled water was added drop wise to 5.0 mmole of $\mathrm{Cr}\left(\mathrm{NO}_{3}\right)_{3}$ in $40 \mathrm{ml}$ of distilled water in a $200 \mathrm{ml}$ reaction vessel. After the last drop of $\mathrm{NaOH}$ solution, the reaction was stirred for 30 min. Thereafter $2.0 \mathrm{~g}$ lophira alata carbonized sawdust was added into the reaction vessel and stirred continuously for another 120 minutes at $90{ }^{\circ} \mathrm{C}$ (using Stuart SD162 heat-stir magnetic stirrer) at $1300 \mathrm{rpm}$, until a consistent dark-greyish colloidal suspension was formed. This was stirred for another $2 \mathrm{hr}$. The CLN formed was allowed to cool down for $6 \mathrm{hr}$, rinsed three times with sufficient distilled water and dried for $6 \mathrm{hr}$ in an oven at $105^{\circ} \mathrm{C}$ and cooled in desiccators for $24 \mathrm{hr}$. The capping process was the same as that of $\mathrm{CN}$.

\subsection{Physicochemical Characterization Techniques}

The physicochemical characterization of the synthesized CN and CLN were evaluated using x-ray diffractograms (XRD, Emphyrean diffractometer system equipped with a copper tube); scanning electron microscope (SEM; Phenom pro suite desktop scanning electron microscope) was used for the images which revealed their morphologies and Fourier Transform infrared spectrophotometer (FTIR) was used to determined the functional groups present.

\subsection{Adsorption Isotherm Studies}

The effect of concentration, adsorbent dose, time, and $\mathrm{pH}$ on the removal of $\mathrm{Cd}^{2+}$ and $\mathrm{Pb}^{2+}$ were investigated. The adsorption process of $\mathrm{Cd}^{2+}$ and $\mathrm{Pb}^{2+}$ ions onto $\mathrm{CN}$ and CLN were studied using the batch adsorption isotherm experiments. $\mathrm{Cd}^{2+}$ and $\mathrm{Pb}^{2+}$ ions concentrations were varied from 10 to $50 \mathrm{mg} / \mathrm{l}$, at optimum $\mathrm{CN}$ dose, contact time, $\mathrm{pH}$ and agitation speed of $300 \mathrm{rpm}$ to obtain the optimum concentration of $\mathrm{Cd}^{2+}$ ions adsorbed. $\mathrm{Pb}^{2+}$ ions were also treated in the same manner. The equilibrium concentration of the heavy metal ions in the treated samples were determined using atomic absorption spectrophotometer (Buck scientific model VGP-210).

\subsection{Adsorption Isotherm Model}

An adsorption process can be best understood by use of isotherm models. Adsorption isotherm is a graph that associates the amount of adsorbed substance (adsorbate) on the adsorbent as a function of pressure (for gases) or 
concentration (for liquids) at constant temperature with the unabsorbed substance concentration (equilibrium concentration, $\mathrm{C}_{\mathrm{e}}$ ) in the solution. Information on the affinity between the adsorbent-adsorbate, adsorption capacity of the adsorbent, surface area, porosity and adsorption heat can be obtained from adsorption isotherms (Yildiz 2017).

The equilibrium amount of adsorbate adsorbed (or adsorption capacities) and adsorption efficiency from the aqueous solution were calculated using equations 1 and 2 respectively:

$\mathrm{q}_{\mathrm{e}}=\frac{\left(\mathrm{C}_{\mathrm{o}}-\mathrm{C}_{\mathrm{e}}\right) \mathrm{v}}{\mathrm{M}}$

$$
\% \mathrm{E}=\frac{\mathrm{C}_{\mathrm{o}}-C_{e}}{\mathrm{C}_{\mathrm{o}}} \times 100
$$

Where $\mathrm{q}_{\mathrm{e}}$ is the amount of adsorbate adsorbed at equilibrium $(\mathrm{mg} / \mathrm{g}) ; \mathrm{C}_{\mathrm{o}}$ is the initial concentration of adsorbate $(\mathrm{mg} / \mathrm{l}) ; \mathrm{C}_{\mathrm{e}}$ is the equilibrium concentration of adsorbate $(\mathrm{mg} / \mathrm{l})$ left in solution; $\mathrm{M}$ is the adsorbent mass (g); and V is the volume of the aqueous solution (1) (Kocaoba et al. 2007; Erdem et al. 2004).

The data obtained from the adsorption processes were analyzed using the Langmuir, Freundlich, DubininRadushkevick (DRK), Temkim and Flory-Huggins adsorption isotherm model.

\subsection{Response Surface Methodology (RSM) Analysis}

Response surface methodology - an empirical modeling technique derived for the evaluation of the relationship of a set of controlled experimental factors and observed results was utilized and a 'Three-factor-three-level' BoxBehnken Design (BBD) was adopted in order to study the response pattern and determine the optimum combination of the initial metal concentration, adsorbent dosage and contact time for optimizing the amounts of lead and cadmium ions adsorbed from their aqueous solutions using the capped CN and CLN adsorbents (Myers et al. 2009).

The values of the process variables considered for these analyses is shown in Tables 1

Table 1. Coded and Actual Levels of the factors for the three factor BBD (CN \&CLN)

\begin{tabular}{cccccc}
\hline Independent variables & Unit & Symbol & \multicolumn{2}{c}{ Coded and actual value } \\
\hline & & & -1 & 0 & 1 \\
Initial concentration & $\mathrm{mg} / 1$ & $\mathrm{X}_{1}$ & 10 & 30 & 50 \\
Adsorbent dosage & $\mathrm{g}$ & $\mathrm{X}_{2}$ & 0.01 & 0.03 & 0.05 \\
Contact time & $\mathrm{min}$ & $\mathrm{X}_{3}$ & 20 & 60 & 100
\end{tabular}

A total of 15 experimental runs with three variables for each individual responses was designed according to BBD of Design Expert 8.6.0 using 3 center points. A Box Behnken experimental design matrix with responses is shown in Tables $2 \mathrm{a} \& 2 \mathrm{~b}$

Table 2a: Box Behnken Experimental Design Matrix with Responses

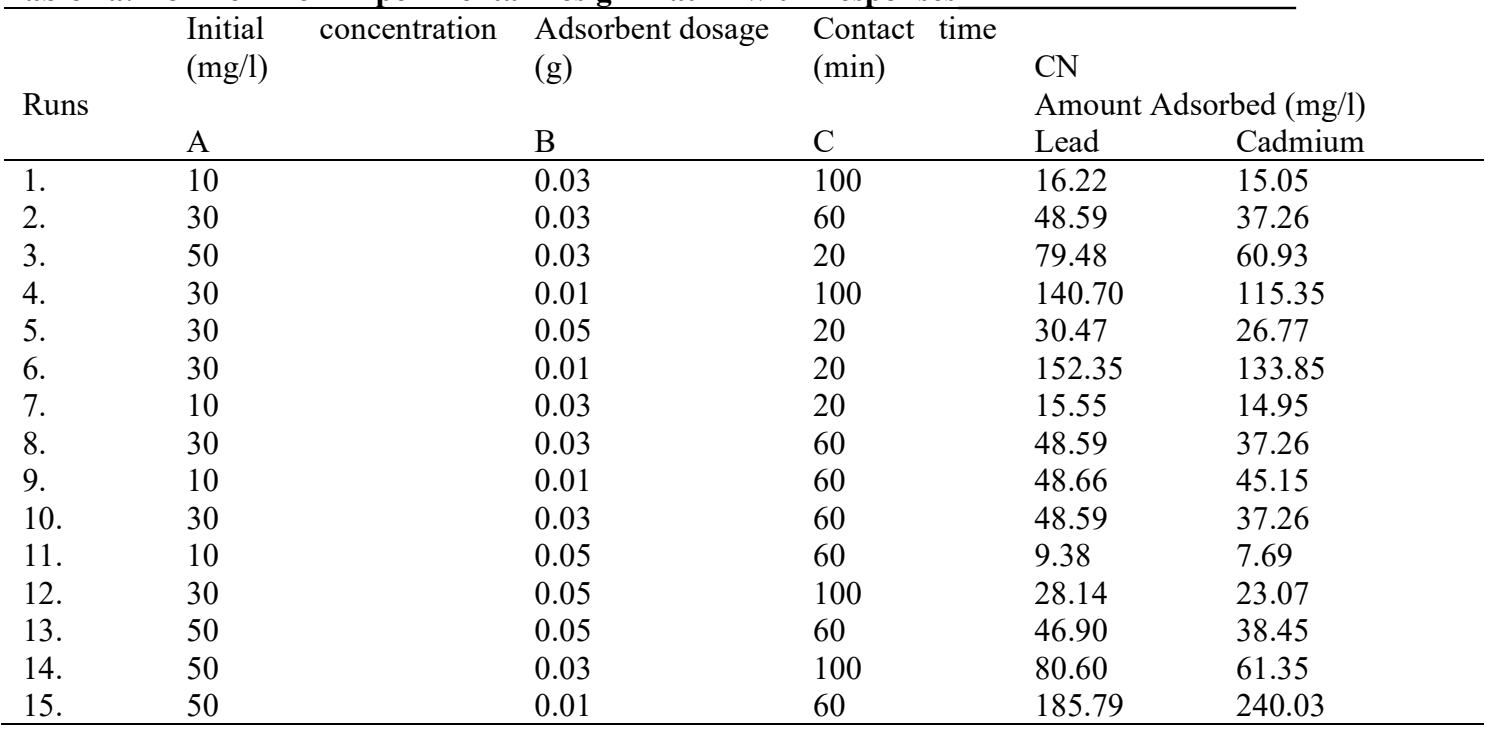


Table 2b: Box Behnken Experimental Design Matrix with Responses

\begin{tabular}{|c|c|c|c|c|c|c|}
\hline \multirow[t]{2}{*}{ Runs } & $\begin{array}{l}\text { Initial } \\
(\mathrm{mg} / \mathrm{l})\end{array}$ & concentration & $\begin{array}{l}\text { Adsorbent dosage } \\
\text { (g) }\end{array}$ & $\begin{array}{l}\text { Contact time } \\
(\min )\end{array}$ & \multicolumn{2}{|c|}{$\begin{array}{l}\text { CLN } \\
\text { Amount Adsorbed (mg/l) }\end{array}$} \\
\hline & $\mathrm{A}$ & & $\mathrm{B}$ & $\mathrm{C}$ & Lead & Cadmium \\
\hline 1. & 10 & & 0.03 & 100 & 10.15 & 12.30 \\
\hline 2. & 30 & & 0.03 & 60 & 49.04 & 6.95 \\
\hline 3. & 50 & & 0.03 & 20 & 40.88 & 6.45 \\
\hline 4. & 30 & & 0.01 & 100 & 147.40 & 20.85 \\
\hline 5. & 30 & & 0.05 & 20 & 14.71 & 2.09 \\
\hline 6. & 30 & & 0.01 & 20 & 49.04 & 6.95 \\
\hline 7. & 10 & & 0.03 & 20 & 8.14 & 1.49 \\
\hline 8. & 30 & & 0.03 & 60 & 49.04 & 6.95 \\
\hline 9. & 10 & & 0.01 & 60 & 48.85 & 8.99 \\
\hline 10. & 30 & & 0.03 & 60 & 49.04 & 6.95 \\
\hline 11. & 10 & & 0.05 & 60 & 9.77 & 1.80 \\
\hline 12. & 30 & & 0.05 & 100 & 13.13 & 67.48 \\
\hline 13. & 50 & & 0.05 & 60 & 7.88 & 37.49 \\
\hline 14. & 50 & & 0.03 & 100 & 50.75 & 61.52 \\
\hline 15. & 50 & & 0.01 & 60 & 245.25 & 38.69 \\
\hline
\end{tabular}

\section{Results and Discussion}

\subsection{Characterization of CN and CLN}

The scanning electron microscope (SEM) images of CL, CN and CLN are shown in Fig. 1a-1c .

Physico-chemical Properties of Lophira Alata Carbonized Sawdust (CL), Chromic Oxide Nanoparticle (CN) and Chromic Oxide-Lophira Alata Carbonized Sawdust Nanocomposite (CLN):
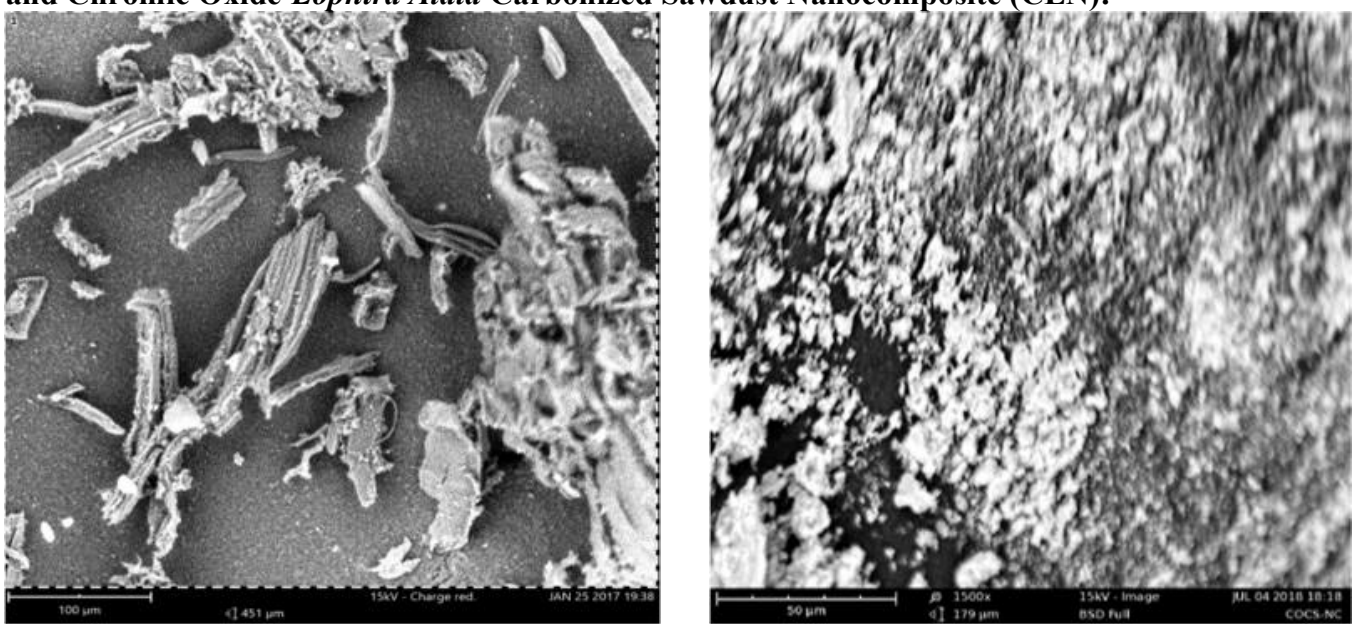

Fig 1a: SEM Image of Lophira Alata carbonized Sawdust (CL).

Fig 1c: SEM Image of Chromic Oxide-Lophira Alata Carbonized Sawdust Nanocomposite (CLN) 


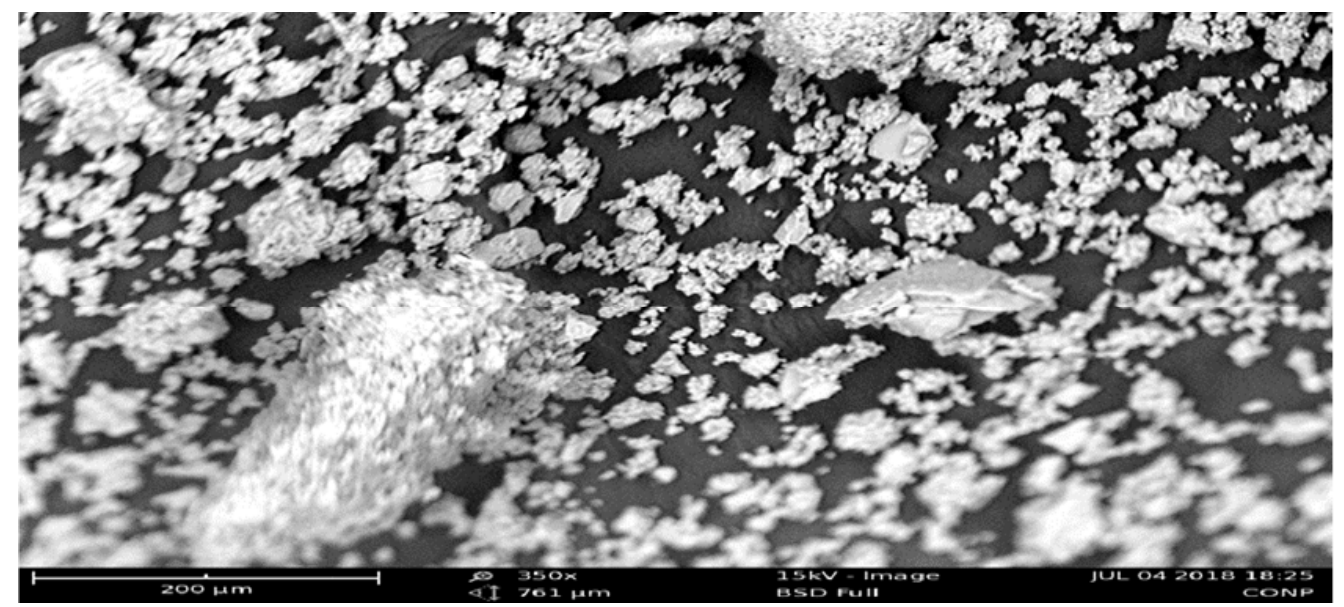

Fig 1b: SEM Image of Chromic Oxide Nanoparticle (CN)

The SEM showed that the surface of the carbonized Lophira alata (CLN) (Fig 1c) possesses rough surface morphology with some pores and has a fibre-like structure which is characteristic of agro- waste. The seemingly rough surface of the carbonized sawdust is an indication of high surface area. In contrast, the SEM of CN and CLN (Fig. 1a \& 1b) were found to be smooth and spherical in shape with very small particles in apparently small agglomerates. The SEM study showed that the $\mathrm{CN}$ is in pure form and the particles are beautiful with coloured nanoparticles.

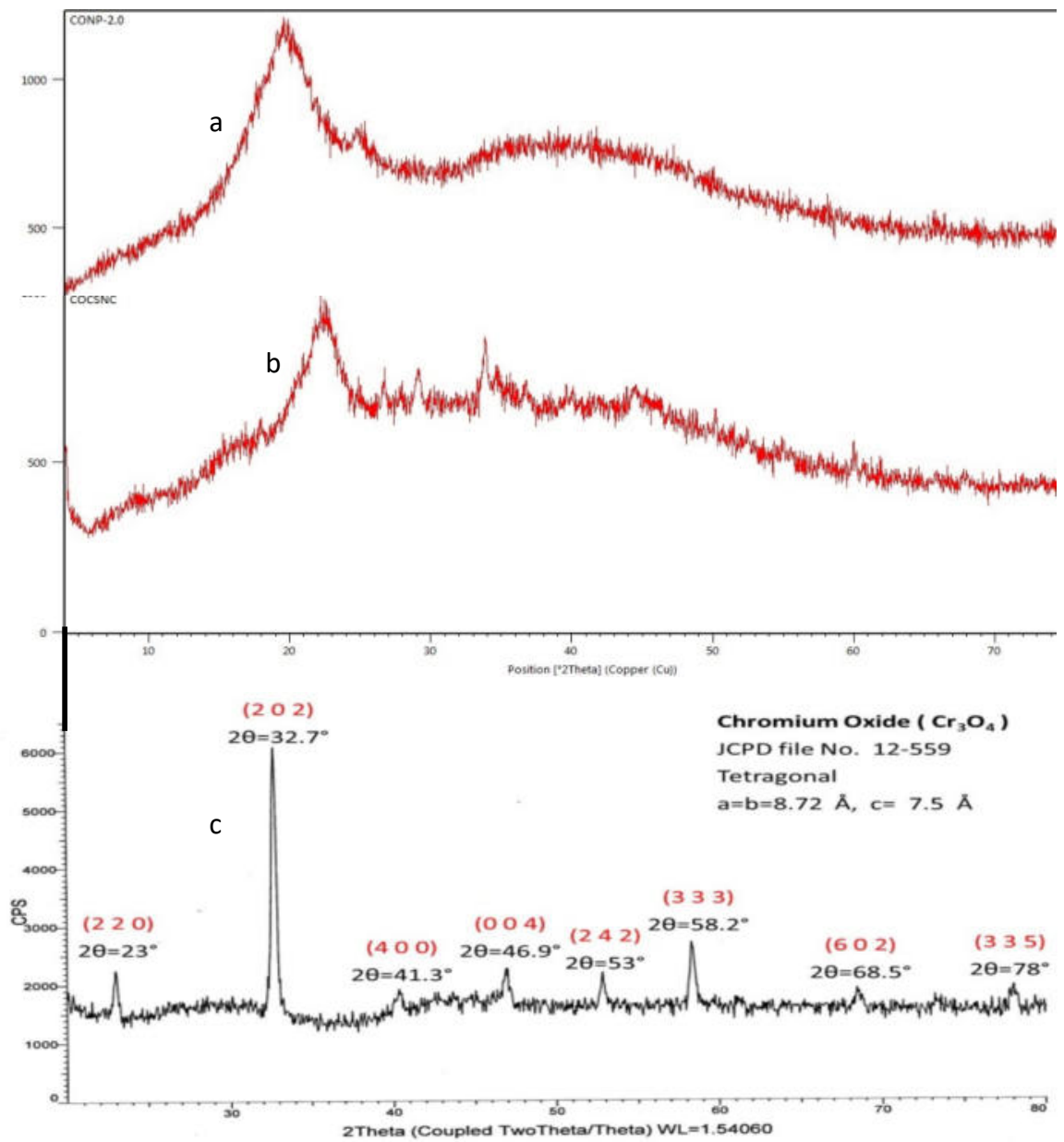

Fig. 2: XRD Image of Chromic oxide nanoparticle (a), chromic oxide-Lophira Alata carbonised sawdust nanocomposite (b) and chromic oxide standard (c).

In the $\mathrm{x}$-ray diffraction of $\mathrm{CN}$ and $\mathrm{CLN}$, some prominent peaks were considered and corresponding d-values 
were compared with standard. The x-ray diffraction pattern of CN and CLN (Fig 2a and b) showed peaks due to $\mathrm{Cr}_{2} \mathrm{O}_{3}$ nanoparticles (Fig 2a) and chromic oxide Lophira alata nanocomposite. No peak was detected due to any other material or phase, indicating a high degree of purity of the synthesized CN and CLN. The broadening of the $\mathrm{x}$-ray diffraction lines, as seen in the Fig. $2 \mathrm{a} \& \mathrm{~b}$ showed that the nanoparticles were amorphous and the sharpness of the peaks shows better crystallinity and good crystal growth of the oxide nanoparticles. Average particle size (L) of the particles was calculated from the high intensity peak using the Debye-Scherer equation.

$$
\mathrm{L}=\mathrm{K} \lambda / \mathrm{B} \cos \Theta
$$

$\mathrm{L}=$ particle size, $\mathrm{B}(2 \Theta)=$ full width at half maximum (FWHM, the broadening of the $\mathrm{x}$-ray peak, in radians), $\mathrm{K}=$ Scherer constant $(0.94), \lambda$ is the $\mathrm{x}$-ray wavelength, and $\Theta$ is the peak position in degree. The particle sizes were found to be 7.7 and $12.05 \mathrm{~nm}$ for $\mathrm{CN}$ and CLN respectively.
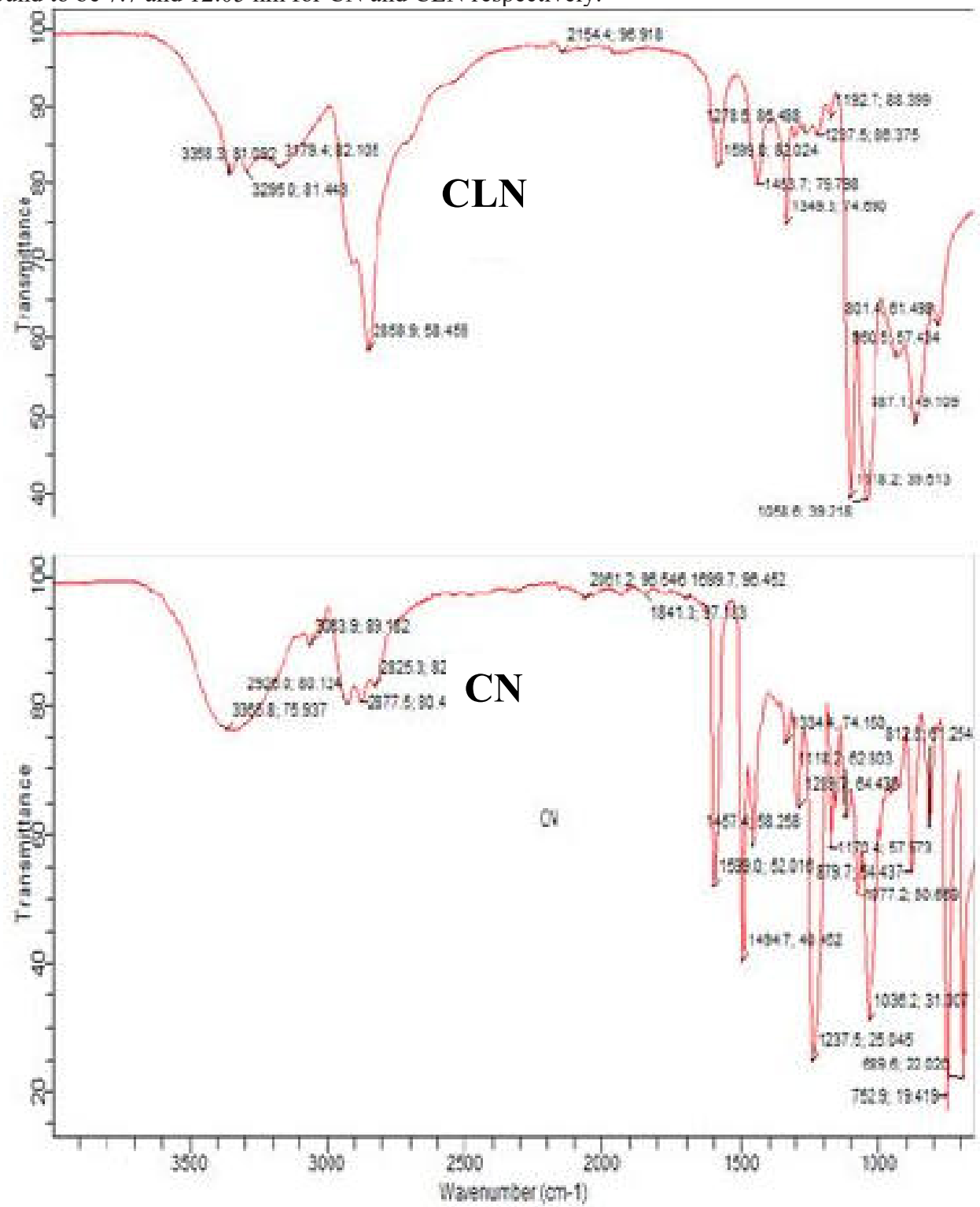

Fig: 3. Fourier Transform Infrared Spectrum of Chromic oxide-Lophira Alata carbonised Sawdust nanocomposite and Chromic oxide Nanopartcle.

The functional groups identified on chromic oxide nanoparticle $(\mathrm{CN})$ FTIR spectrum, are $\mathrm{O}-\mathrm{H},-\mathrm{NH},-\mathrm{CONH}_{2}$ and $-\mathrm{C}=\mathrm{C}-\left(\right.$ arene) . That of $\mathrm{CLN}$ is $\mathrm{O}-\mathrm{H},-\mathrm{NH},-\mathrm{NH}_{2},-\mathrm{C} \equiv \mathrm{N},-\mathrm{CONH}_{2}$ and $-\mathrm{C} \equiv \mathrm{CH}$ (Fig. 3). These will promote negatively-surface-charged character of $\mathrm{CN}$ due to availability of electrons, hence increasing its chances of removing heavy metals from polluted waters. The $\mathrm{C}-\mathrm{O}$ stretch bond on $\mathrm{CN}$ and CLN belonging to the carboxylic acid groups can also result in the formation of negatively-charged carboxylate ions ( $\left.\mathrm{COO}^{-}\right)$with a strong coordinative affinity in forming chelate complexes towards metal ions (Shen et al. 2009). The metal oxide (M-O- 
$\mathrm{M}$; $\mathrm{Cr}-\mathrm{O}-\mathrm{Cr}$ ) functional group infers the presence of chromic oxide. In acidic solution chromic oxide $\left(\mathrm{Cr}^{3+}\right)$ is always octahedral hexaquo ion, $\mathrm{Cr}\left(\mathrm{H}_{2} \mathrm{O}\right)_{6}{ }^{3+}$. It tends to hydrolyze with increasing $\mathrm{pH}$, resulting in the formation of polynuclear complexes containing $\mathrm{OH}^{-}$bridges which can greatly increase the negative charges on the surface of $\mathrm{CN}$ and CLN, hence promoting its ability to adsorb heavy metals from polluted water (Weckhuysen et al. 1996).

\subsection{Adsorption Study and Response Surface Methodology (RSM) Analysis}

The isotherm parameters determined from the slope and the intercepts of the linear plots of the adsorption isotherms and response surface methodology (RSM) analysis (Table 4; Fig 4a - d) were used in predicting the removal behavior and adsorption efficiency of the $\mathrm{Cd}^{2+}$ and $\mathrm{Pb}^{2+}$ ions by $\mathrm{CN}$ and CLN adsorbents.

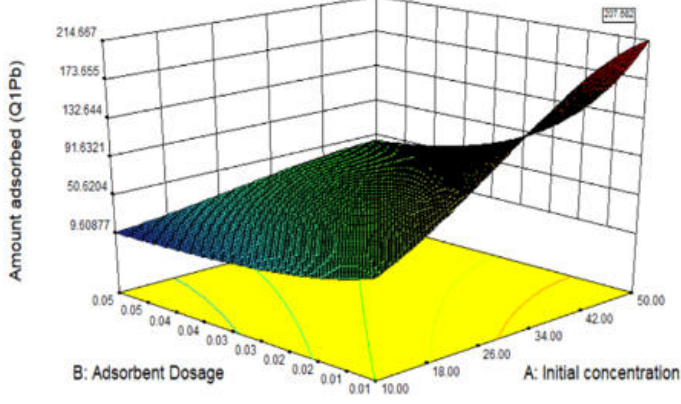

a

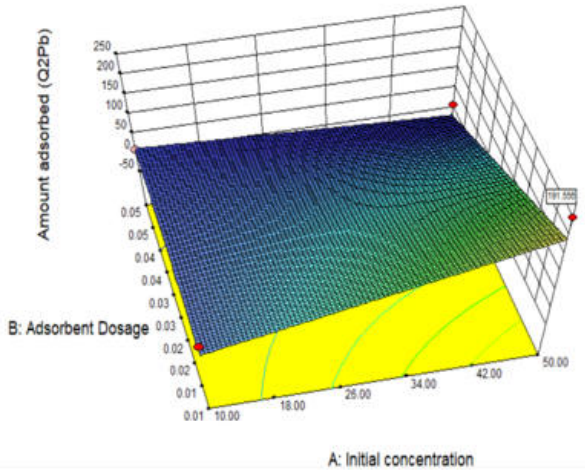

c

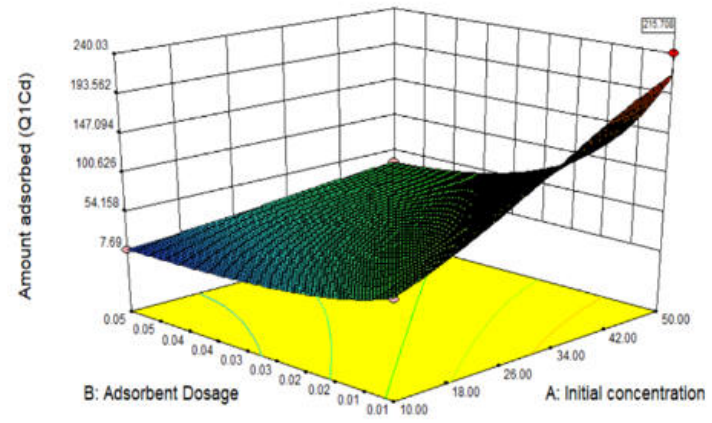

b

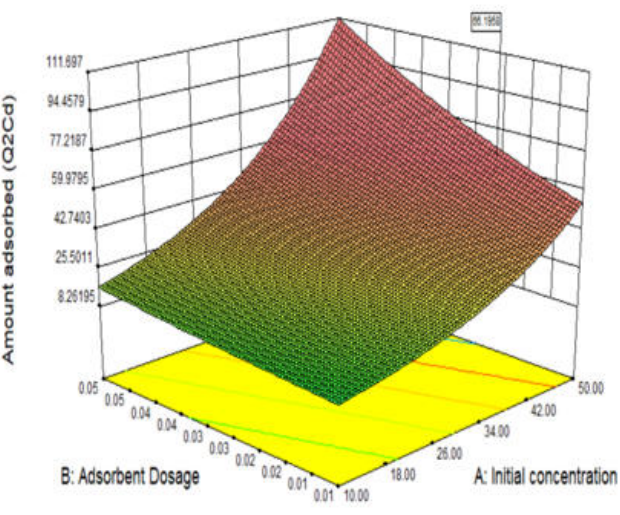

d

Fig. 4: Response surface plots showing the interaction effects of initial concentration and adsorbent dosage on the amounts of (a) lead (b) cadmium adsorbed by the CN and (c) lead (d) cadmium adsorbed by CLN adsorbents.

The isotherm parameters obtained from the adsorption isotherm and response surface methodology (RSM) analysis is presented in the Table $4 \mathrm{a} \& \mathrm{~b}$ : 
Table 4a: Isotherm parameter models and response surface methodology (RSM) Analysis value obtained for adsorption of $\mathrm{Cd}^{2+}$ and $\mathrm{Pb}^{2+}$ ions onto $\mathrm{CN}$

\begin{tabular}{|c|c|c|c|}
\hline Models & Parameters & $\mathrm{Cd}^{2+}$ & $\mathrm{Pb}^{2+}$ \\
\hline \multirow[t]{4}{*}{ Langmuir isotherm model } & $\mathrm{q}_{\mathrm{mL}}(\mathrm{mg} / \mathrm{g})$ & 78.74 & 370.37 \\
\hline & $\mathrm{K}_{\mathrm{L}}(1 / \mathrm{mg})$ & 0.17 & 0.17 \\
\hline & $\mathrm{R}_{\mathrm{L}}$ & 0.10 & 0.11 \\
\hline & $\mathrm{R}^{2}$ & 0.87 & 0.70 \\
\hline \multirow[t]{3}{*}{ Freundlich isotherm model } & $\mathrm{K}_{\mathrm{F}}$ & 59.52 & 51.99 \\
\hline & $\mathrm{n}_{\mathrm{F}}$ & 1.97 & 1.15 \\
\hline & $\mathrm{R}^{2}$ & 0.98 & 0.99 \\
\hline \multirow{4}{*}{$\begin{array}{l}\text { Dubinin-Radush-kervik (DRK) Isotherm } \\
\text { model }\end{array}$} & $\mathrm{q}_{\mathrm{mD}}(\mathrm{mg} / \mathrm{g})$ & 71.16 & 75.24 \\
\hline & $\beta\left(\mathrm{mol}^{2} \mathrm{~J}^{-2}\right)$ & $-6 \times 10^{-8}$ & $-1 \times 10^{-8}$ \\
\hline & $\mathrm{E}\left(\mathrm{KJ} \mathrm{mol}^{-1}\right)$ & 2.89 & 7.07 \\
\hline & $\mathrm{R}^{2}$ & 0.84 & 0.89 \\
\hline \multirow[t]{4}{*}{ Temkin Isotherm model } & $\mathrm{b}\left(\mathrm{J} \mathrm{mg}^{-1}\right)$ & 155.62 & 72.38 \\
\hline & B $\left(1 g^{-1}\right)$ & 16.03 & 34.46 \\
\hline & $\mathrm{K}_{\mathrm{T}}$ & 2.13 & 5.21 \\
\hline & $\mathrm{R}^{2}$ & 0.89 & 0.96 \\
\hline \multirow[t]{4}{*}{ Flory-Huggins isotherm model } & $\mathrm{K}_{\mathrm{FH}}$ & $2.09 \times 10^{-3}$ & $2.96 \times 10^{-3}$ \\
\hline & $\mathrm{n}_{\mathrm{FH}}$ & 1.64 & 15.29 \\
\hline & $\Delta G^{o}(\mathrm{~kJ})$ & -15.39 & 129.05 \\
\hline & $\mathrm{R}^{2}$ & 0.95 & 0.19 \\
\hline Response Surface Methodology (RSM) & Optimal values & & \\
\hline \multirow[t]{5}{*}{ Analysis } & Initial Concentration $(\mathrm{mg} / \mathrm{l})$ & 50.00 & 47.93 \\
\hline & Adsorbent dosage (g) & 0.01 & 0.01 \\
\hline & Contact time $(\mathrm{min})$ & 60.00 & 67.10 \\
\hline & Amount adsorbed (mg/g) & 215.71 & 206.34 \\
\hline & $\mathrm{R}^{2}-\mathrm{R}$ squared & 0.94 & 1.00 \\
\hline
\end{tabular}

Langmuir isotherm revealed that $\mathrm{CN}$ has a higher adsorption capacity for $\mathrm{Pb}^{2+}$ ions as obtained from $\mathrm{DRK}$ isotherm. Their adsorption must have taken place only at localized sites on its surface. $\mathrm{Pb}^{2+}$ and $\mathrm{Cd}^{2+}$ ions had high heat of adsorption, high binding affinity on the adsorbent and the immobilization of the adsorbate onto the sorbent was favorable (Table 4a). The Langmuir isotherm was not favorable for the description of the adsorption process in CLN because the $\mathrm{R}^{2}$ value was too low (Table $4 \mathrm{~b}$ ).

Freundlich isotherm revealed that there was no monolayer adsorption but a multilayer adsorption properties consisting of heterogeneous surface of the adsorbent in terms of adsorption regions and energy. The adsorption is a physical process for both adsorbents and it indicated a favorable adsorption process for $\mathrm{Cd}^{2+}$ and $\mathrm{Pb}^{2+}$ ions based on their $n_{F}$ values. The higher the value of $n_{F}$, the better its adsorption mechanism and formation of relatively stronger bonds. 
Table 4b: Isotherm parameter models and response surface methodology (RSM) Analysis value obtained for adsorption of $\mathrm{Cd}^{2+}$ and $\mathrm{Pb}^{2+}$ ions onto CLN

\begin{tabular}{|c|c|c|c|}
\hline Models & Parameters & $\mathrm{Cd}^{2+}$ & $\mathrm{Pb}^{2+}$ \\
\hline \multirow{4}{*}{ Langmuir isotherm model } & $\mathrm{q}_{\mathrm{mL}}(\mathrm{mg} / \mathrm{g})$ & 50.25 & 1428.57 \\
\hline & $\mathrm{K}_{\mathrm{L}}$ & 0.12 & 0.16 \\
\hline & $\mathrm{R}_{\mathrm{L}}$ & 0.14 & 0.11 \\
\hline & $\mathrm{R}^{2}$ & 0.46 & 0.16 \\
\hline \multirow[t]{3}{*}{ Freundlich isotherm model } & $\mathrm{K}_{\mathrm{F}}$ & 8.08 & 278.04 \\
\hline & $\mathrm{n}_{\mathrm{F}}$ & 1.94 & 0.40 \\
\hline & $\mathrm{R}^{2}$ & 0.82 & 0.97 \\
\hline \multirow{4}{*}{$\begin{array}{l}\text { Dubinin -Radush-kervik (DRK) Isotherm } \\
\text { model }\end{array}$} & $\mathrm{q}_{\mathrm{mD}}(\mathrm{mg} \mathrm{g}-1)$ & 25.09 & 329.77 \\
\hline & $\beta\left(\mathrm{mol}^{2} \mathrm{~J}^{-2}\right)$ & $-4.00 \times 10^{-7}$ & $-1.00 \times 10^{-7}$ \\
\hline & $\mathrm{E}\left(\mathrm{KJ} \mathrm{mol}^{-1}\right)$ & 1.12 & 2.24 \\
\hline & $\mathrm{R}^{2}$ & 0.63 & 0.99 \\
\hline \multirow[t]{4}{*}{ Temkin Isotherm model } & $\mathrm{b}\left(\mathrm{J} \mathrm{mg}^{-1}\right)$ & 266.15 & 18.46 \\
\hline & $\mathrm{B}\left(1 \mathrm{~g}^{-1}\right)$ & 9.37 & 135.09 \\
\hline & $\mathrm{K}_{\mathrm{T}}$ & 1.92 & 6.01 \\
\hline & $\mathrm{R}^{2}$ & 0.64 & 0.98 \\
\hline \multirow[t]{4}{*}{ Flory-Huggins isotherm model } & $\mathrm{K}_{\mathrm{FH}}$ & 0.06 & 2113.49 \\
\hline & $\mathrm{n}_{\mathrm{FH}}$ & 1.25 & 3.24 \\
\hline & $\Delta G^{o}(\mathrm{~kJ})$ & -7189.29 & 19095.83 \\
\hline & $\mathrm{R}^{2}$ & 0.64 & 0.39 \\
\hline \multirow{6}{*}{$\begin{array}{l}\text { Response Surface Methodology (RSM) } \\
\text { Analysis }\end{array}$} & Optimal values & & \\
\hline & Initial Concentration (mg/l) & 49.29 & 50.00 \\
\hline & Adsorbent dosage (g) & 0.02 & 0.01 \\
\hline & Contact time (min) & 99.93 & 60.00 \\
\hline & Amount adsorbed (mg/g) & 66.20 & 191.50 \\
\hline & $\mathrm{R}^{2}-\mathrm{R}$ squared & 1.00 & 0.76 \\
\hline
\end{tabular}

This implies that $\mathrm{Cd}^{2+}$ ions formed the relatively stronger bonds with the adsorbent $\mathrm{CN}$ and CLN and a better adsorption mechanism. However, $\mathrm{K}_{\mathrm{F}}$ value for $\mathrm{Pb}^{2+}$ revealed that it had a stronger adsorption capability in the adsorbent CLN.

The Dubinin- Radush-Kevick (DRK) isotherm revealed that the adsorption of $\mathrm{Cd}^{2+}$ and $\mathrm{Pb}^{2+}$ ions were exothermic. The activity coefficient constant $(\beta)$ for $\mathrm{Pb}^{2+}$ ions is low, thus supporting the fact that the adsorption capacity of lead ions was relatively higher than that of $\mathrm{Cd}^{2+}$ ions. The mean free energy or energy of affinity (E) between the adsorbate and the adsorbent was in favour of $\mathrm{Pb}^{2+}$ ions hence confirming the higher adsorption capacity $\left(\mathrm{q}_{\mathrm{m}}\right)$ of the lead ions onto the capped $\mathrm{CN}$ and CLN adsorbents (Table $4 \mathrm{a} \& \mathrm{~b}$ ). The sorption process of the adsorbate $\mathrm{Pb}^{2+}$ and $\mathrm{Cd}^{2+}$ on the capped $\mathrm{CN}$ and CLN adsorbents is a physical process since the $\mathrm{E}$ value calculated from the DRK isothermal model is lower than $8 \mathrm{~kJ} / \mathrm{mol}$ thus agreeing with the prediction from Freundlich isotherm model.

Temkin isotherm showed that $\mathrm{Pb}^{2+}$ ions had higher adsorption potential or maximum binding energy ( $\mathrm{B}$ and $\mathrm{K}_{\mathrm{T}}$ ) to the capped $\mathrm{CN}$ and $\mathrm{CLN}$ adsorbents. This indicated that $\mathrm{Pb}^{2+}$ ions had higher adsorption capacity onto the capped $\mathrm{CN}$ and CLN adsorbents and this was corroborated by the heat of adsorption (b) value which shows that the $\mathrm{Pb}^{2+}$ ion has the stronger interaction with the adsorbents, hence a higher adsorption capacity onto the adsorbents. This value agrees with the prediction from Langmuir and DRK isotherm models. The values of the calculated $\mathrm{b}$ were positive for $\mathrm{Cd}^{2+}$ and $\mathrm{Pb}^{2+}$ an indication that the reaction is exothermic and a physiosorption process.

The Flory-Huggins isotherm fitted well to the sorption data of $\mathrm{Cd}^{2+}$ ions on $\mathrm{CN}$, but the reverse is the case for CLN. The removal of $\mathrm{Pb}^{2+}$ ions had a $\mathrm{R}^{2}$ value well below 0.7 hence its sorption data could not be interpreted using the Flory-Huggins isothermal model and the calculated standard free energy $\left(\Delta G^{o}\right)$ revealed that the adsorption process is spontaneous and supports exothermic nature for $\mathrm{Cd}^{2+}$ ions.

\section{Optimization}


For the entire range of initial concentration investigated, the $\mathrm{Cd}^{2+}$ and $\mathrm{Pb}^{2+}$ ions removal generally increased with contact time. This suggests that the extent of sorption onto the surface of the adsorbents is a function of time. From Table $4 \mathrm{a}$ and $\mathrm{b}$ (Fig.4a and b), it was observed that at a contact time of $67.10 \mathrm{~min}$, initial concentration of $50 \mathrm{mg} / 1$ and adsorbent dosage of $0.01 \mathrm{~g}$, the optimum amount of $\mathrm{Pb}^{2+}$ ions adsorbed onto $\mathrm{CN}$ was $206.34 \mathrm{mg} / \mathrm{g}$ while that of $\mathrm{Cd}^{2+}$ ions at the same initial concentration and contact time of $60 \mathrm{~min}$ was $215.71 \mathrm{mg} / \mathrm{g}$. From these observations, the interaction between initial concentration and adsorbent dosage have an overall positive impact on the adsorption of $\mathrm{Pb}^{2+}$ and $\mathrm{Cd}^{2+}$ ions by the $\mathrm{CN}$ adsorbent and the $\mathrm{Cd}^{2+}$ ions was slightly more adsorbed.

The 3 - D response surface plots for $\mathrm{Pb}^{2+}$ and $\mathrm{Cd}^{2+}$ ions adsorbed onto CLN is presented in Fig. $4 \mathrm{c}$ and $\mathrm{d}$. In the same vein, the amount of $\mathrm{Pb}^{2+}$ ions adsorbed under the same adsorption parameters was of the similar magnitude while tha of $\mathrm{Cd}^{2+}$ ions was 3 - folds higher at the contact time of $99.93 \mathrm{~min}$ and adsorbent dosage of 0.02 .

\section{Conclusion}

The synthesized $\mathrm{CN}$ and CLN adsorbents adsorbed $\mathrm{Pb}^{2+}$ and $\mathrm{Cd}^{2+}$ ions favorably and exothermically through a physical process (physiosorption). The adsorption isotherm revealed that both adsorbents had higher adsorption capacity for $\mathrm{Pb}^{2+}$ ions. However, the optimization study revealed that the cadmium ions were slightly more adsorbed by $\mathrm{CN}$ while $\mathrm{Cd}^{2+}$ ions are more favoured by CLN. This observation is in agreement with the $\mathrm{k}_{\mathrm{F}}$ values obtained from Freundlich isotherm.

\section{Acknowledgements}

The authors thank tetfund for providing fund for this research work. We also acknowledge the Department of Chemistry for providing the enabling environment for the research work.

\section{References}

Cornell R.M., Schwertmann U., 2003. The Iron Oxide: Structure, Properties, Reactions, Occurrences and Uses. Wiley-VCH, Weinheim, Germany;

Erdem, E., Karapinar, N., Donat, R., 2004. The removal of Heavy Metal Cations by Natural Zeolites. J. Colloid. Interface. Sci. 280, 309-314. http://doi.org/10.1016/j.jcis.2004.08.028.

Hasanzadeh, M., Ansari, R. and Ostovar, F. 2016. Synthesis and application of $\mathrm{CeO}_{2}$ /sawdust nanocomposite for removal of As(III) ions from aqueous solutions using a fixed bed column system. Global Nest Journal. 19(1), $7-16$

Kocaoba, S., Orhan Y., AkyüzT., 2007. Kinetics and Equilibrium Studies of Heavy Metal Ions Removal by Use of Natural Zeolite. Desalination 214, 1-10. http://doi.org/10.1016/j.desal.2006.01.023.

Li L., Mak K. Y., Leung C. W., Chan K. Y., Chan W. K., Zhong W., Pong P.W.T., 2013. Effect of Synthesis Conditions on the Properties of Citric Acid Coated Iron Oxide Nanoparticles. Microelectronic EngineeringElsevier 110, 329-334. http://doi.org/10.1016/j.mee.2013.02.045.

Mahdi Y., Seyede F. H., Atena H., Alireza G., Valiollah A., 2012. The effect of nanoparticle ZnO on Environment and Different Organism. International Journal of Plant, Animal and Environmental Sciences2(3).

Moafi, H.F., Ansari, R. and Ostovar, F. 2016. Ag2O/Sawdust nanocomposite as an efficient adsorbent for removal of hexavalent chromium ions from aqueous solution. J. Mater. Environ. Sci. 7(6), 2051 - 2068

Mohan, D., Rajputa, S., Singh, V. K., Steele, P. H., Pittman, C. U.,2011. Modeling and Evaluation of Chromium Remediation from Water Using Low Cost Bio-char, a Green Adsorbent. Journal of Hazardous Materials. 188, 319 - 333. http://doi.org/10.1016/j.jhazmat.2011.01.127

Myers, R.H., Montgomery, D.C., Anderson-Cook, C.M., 2009. Response Surface Methodology: Process and Product Optimization Using Designed Experiments. John Wiley \& Sons, Inc., Hoboken, New Jersey, USA.

Rakesh, S. A., Netkal M. M. G., 2013. Synthesis of Chromium (III) Oxide Nanoparticles by Electrochemical Method and Mukia Maderaspatana Plant Extract, Characterization, $\mathrm{KMnO}_{4}$ Decomposition and Antibacterial Study. Modern Research in Catalysis2, 127-135.

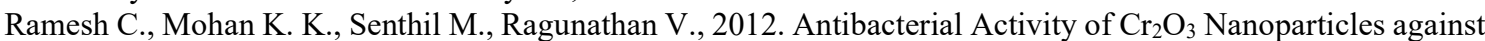
E.coli; Reduction of Chromate Ions by Arachis hypogaea leaves. Archives of Applied Science Research 4(4), 1894-1900.

Rathore P., Phanse N., Patel B., 2012. Nanomaterials: A Future Concern International Journal of Research in Chemistry and Environment. 2(2), 1-7.

Sadegh, H., Shahryari-Ghoshekandi, R. and Kazemi, M. 2014. Study in synthesis and characterization of carbon nanotubes decorated by magnetic iron oxide nanoparticles. Int.Nano Lett., 4, $129-135$.

Sadjadi M. S., Khalilzadegan A.,2015. The Effect of Capping Agents, EDTA and EG on the Structure and Morphology of CdS Nanoparticles. Journal of Non-Oxide Glasses7(4), 55 - 63.

Salata O.V., 2004. Application of Nanoparticles in Biology and Medicine. Journal of Nanobiotechnology. [http://doi.org/10.1186/1477-3155-2-3]. 
Savage, N. and Dillo, M.S. 2005. Nanomaterials and water purification: Opportunities and challenges. Journal of Nanoparticle Research 7, $331-342$.

Shen Y. F., Tang J., Nie Z. H., Wang Y. D., Ren Y., Zuo L., 2009. Preparation and application of magnetic $\mathrm{Fe}_{3} \mathrm{O}_{4}$ nanoparticles for wastewater purification. Sep. Purif. Technol. 68, 312-329. http://doi.org/10.1016/j.seppur.2009.05.020.

Sovan L. P., Utpal J., Manna P. K., Mohanta G. P., Manavalan R., 2011. Nanoparticle: An Overview of Preparation and Characterization. Journal of Applied Pharmaceutical Science. 1(6), 228-234.

Sushma, D. and Richa, S. 2015. Use of nanoparticle in water treatment: A review. International Research Journal of Environment Sciences. 4(10), 103 - 106

Tavares K.P., Caloto-Oliveira Á., Vicentini D.S., Melegari S.P., Matias W.G., Barbosa S., Kummrow F., 2014. Acute Toxicity of Copper and Chromium Oxide Nanoparticles to Daphnia Similis. Ecotoxicol. and Environ. Contam., (EEC) 9(1), 43-50.http://doi.org/10.5132/eec.2014.01.006.

Wani A. H., Shah M. A., 2012. A Unique and Profound Effect of MgO and ZnO Nanoparticles on some Plant Pathogenic Fungi. Journal of Applied Pharmaceutical Science 2(3), 40-44.

Weckhuysen B. M., Wachs I. E., Schoonheydt R. A., 1996. Surface Chemistry and Spectroscopy of Chromium in Inorganic Oxides. Chem. Rev. 96, 3327-3350.http://doi.org/10.1021/cr940044o

Yildiz S.,2017. Kinetic and Isotherm Analysis of $\mathrm{Cu}(\mathrm{II})$ Adsorption onto Almond Shell (Prunus dulcis). Ecol. Chem. Eng. S 24(1), 87-106. http://doi.org/10.1515/eces-2017-0007.' 